\title{
A Clean and Sustainable Cellulose-Based Composite Film Reinforced with Waste Plastic Polyethylene Terephthalate
}

\author{
Airong Xu $\left(\mathbb{D},{ }^{1}\right.$ Yongxin Wang, ${ }^{1}$ Xingmin $X u,{ }^{2}$ Zhihong Xiao, ${ }^{3}$ and Rukuan Liu ${ }^{3}{ }^{3}$ \\ ${ }^{1}$ School of Chemical Engineering \& Pharmaceutics, Henan University of Science and Technology, Luoyang, Henan 471003, China \\ ${ }^{2}$ School of Forensic Medicine, Henan University of Science and Technology, Luoyang, Henan 471003, China \\ ${ }^{3}$ State Key Laboratory of Utilization of Woody Oil Resource, Hunan Academy of Forestry, Changsha, Hunan 410004, China
}

Correspondence should be addressed to Airong Xu; airongxu@haust.edu.cn and Rukuan Liu; liurukuan@gmail.com

Received 2 May 2020; Accepted 11 June 2020; Published 18 July 2020

Academic Editor: Barbara Liguori

Copyright (C) 2020 Airong Xu et al. This is an open access article distributed under the Creative Commons Attribution License, which permits unrestricted use, distribution, and reproduction in any medium, provided the original work is properly cited.

With the widespread use and increasing consumption of PET, the amount of waste PET is growing rapidly, and the accompanied environmental problems will become more and more serious. Therefore, the recycling and reuse of PET are of great significance for not only saving resources but also solving environmental issues. In this study, Methylcellulose (MC) composites reinforced with waste plastics polyethylene terephthalate (PET) were prepared by casting an MC/PET solution with a varying mass ratio of $\mathrm{MC}$ to PET. Systematic investigations were performed to reveal the effect of the MC/PET mass ratio on the mechanical property, chemical structure, and thermal properties. The resultant findings indicate that the addition of 3\% waste plastics PET to MC could notably enhance the tensile strength by about $24 \%$ as compared with neat MC. Interestingly, the elongation of the MC/PET composite kept increasing with increasing waste plastics PET. At the same time, thermal compression treatment could also enhance the mechanical properties of the composite. Moreover, the composites also displayed higher thermal stability than MC. In addition, the crystallinity and morphology of the composite were estimated by XRD and SEM.

\section{Introduction}

Polyethylene terephthalate (PET), an aromatic semicrystalline polymer, has excellent performance characteristics in mechanical strength, inertness to chemical action, resistance to thermal environment, and biocompatibility [1-4]. Based on these excellent performances, PET is widely used for the production of chemical fiber, films, and bottles [5-8]. This polymer has also been employed in medical fields as prosthetic components for producing vascular grafts, aortic root, overdentures, and so on [3]. Interestingly, the properties of PET can be remarkably improved by incorporating nanoscale graphene fillers in PET [9-14]. However, the massive use of PET products also accompanies environmental issues because of unavoidable littering and incinerating after use $[15,16]$. In this context, the recovery and reuse of discarded PET products are of particular significance [17]. At present, some research studies have been conducted to fabricate PET-containing composites by blending recovered PET with polypropylene and polyethylene [18-23].

In the recent years, increasing attention has been paid to environmental-friendly polymer materials produced from renewable biopolymers because of growing concern about environmental issues caused by petroleum-based products such as PET [24-28]. Methylcellulose (MC) is a biopolymer produced by replacing hydrogen atoms of the hydroxyl residues of cellulose backbone by methyl groups [29-31]. Moreover, MC has many attractive properties such as excellent film-making capability, good biodegradability, nontoxicity, and strong mechanical property [31-33]. Based on these excellent properties, MC is widely used in the production of self-repairing coatings, food packaging materials, and high-performance composites [34-37].

However, extensive literature consulting reveals that few studies are available on the composite materials which are fabricated with MC and waste PET. Therefore, in this paper, 
the preparation of an MC/PET composite film was achieved by changing the MC/PET mass ratio. Scanning electron microscopy (SEM), X-ray diffraction (XRD), thermogravimetric analysis (TGA), ${ }^{13} \mathrm{C}$ NMR spectroscopy, and mechanical tests were used to study the microstructure, thermal stability, crystal structure, and mechanical properties of these composite films.

\section{Experiment Section}

2.1. Materials and Fabrication of the MC/PET Film. Polyethylene terephthalate (PET) was taken from a discarded waste bottle. This bottle was cleaned with distilled water and, then, cut into $3 \times 3 \mathrm{~mm}$ of pieces. Methylcellulose (MC) (viscosity of $1600 \mathrm{cPs}$ ) was from Alfa Aesar. Hexafluoroisopropanol (HFIP) (99.5\%) was purchased from Aladdin Biochemical Technology Co., Ltd.

$\mathrm{MC}$ and PET were dissolved in HFIP with mechanical stirring (Magnetic Stirring Apparatus, 98-2, Shanghai Sile Instrument Co., LTD., Shanghai, China) at an ambient temperature to gain an MC/PET/HFIP solution. The total concentration of MC and PET in HFIP was about 1.1 wt.\%. Then, the air bubbles in the MC/PET/HFIP solution were removed by using an ultrasonic apparatus for $20 \mathrm{~min}$. Then, the solution was transferred to a glass mold $(10 \mathrm{~cm} \times 10 \mathrm{~cm})$. A MC/PET (x : y) film was gained followed by volatilizing HFIP, and $\mathrm{x}$ : $\mathrm{y}$ was the MC/PET mass ratio. The obtained MC/PET ( $x: y)$ film was further dried in a vacuum oven for at $50^{\circ} \mathrm{C}$ for the complete evaporation of HFIP residual.

2.2. Characterization. A scanning electron microscope (SEM) was used to observe the internal micromorphology of the MC/PET film sample. The sample film was frozen in liquid nitrogen and, then, snapped. Before observation, the surface of the frozen fracture was sputtered by gold and, then, photographed. X-ray diffraction (XRD) measurement was carried out on a Bruker D8 Advance diffraction spectrometer with $\mathrm{Cu}-\mathrm{Ka}$ radiation $\left(\lambda=1.54^{\prime} \AA\right)$ over the range $3-60^{\circ}(2 \theta)$ at a scan speed of $2^{\circ}(2 \theta)$ per minute. Thermogravimetric analysis (TGA) was performed on a Netzsch STA $449 \mathrm{C}$ thermal gravimetric analyzer at a temperature range of $25^{\circ} \mathrm{C}-600^{\circ} \mathrm{C}$ and a heating rate of $10^{\circ} \mathrm{C}$ per minute under a nitrogen atmosphere. Solid-state ${ }^{13} \mathrm{C}$ NMR was determined with a $400 \mathrm{MHz}$ NMR spectrometer (Bruker Advance III, Germany).

\subsection{Measurement of Tensile Strength and Elongation at Break.} The sample films were cut into dumbbell-shaped specimens of $75 \mathrm{~mm}$ length and, then, kept in a dryer with a saturated $\mathrm{NaCl}$ solution $(\mathrm{RH}=75 \%)$ for $24 \mathrm{~h}$. A WDW-10 universal tensile tester was used to measure the tensile strength and elongation at break according to ISO 527-3, 1995 (E), with an extension rate of $2 \mathrm{~mm} \mathrm{m^{-1 }}$ and a gauge length of $20 \mathrm{~mm}$. Tensile strength and elongation at break values were averages of five measurements.

\section{Results and Discussion}

3.1. Morphology. Scanning electron microscopy (SEM) was used to study the morphology of the MC and MC/PET films, and SEM images are given in Figure 1. It is known that MC is hydrophilic, and hydrophobic for PET. Therefore, MC is not mutually soluble with PET, which has been observed from Figure 1. Different from a neat MC film which shows a homogeneous and dense morphological structure, an obvious phase separation between MC and PET is observed for all the MC/PET films (see Figures 1(b)-1(i)). It can be observed from Figures 1(b) and 1(c) that PET in the $\mathrm{MC} /$ PLA (99:1) and MC/PLA (97:3) films is conglomerated into a very few bead-like shape, and these bead-like PET are distributed throughout the MC matrix phase. By comparison, bigger size of ball-like PET in the MC/PLA (95:5), MC/ PLA (9:1), MC/PLA (7:3), MC/PLA (1:1), MC/PLA (3:7), and MC/PLA $(9: 1)$ films is covered by a layer of MC (see Figures 1(d)-1(i)).

3.2. ${ }^{13} \mathrm{C}$ NMR Spectroscopy. The solid-state NMR spectra of $\mathrm{MC}$, raw PET, and MC/PET (1:1) composite films are shown in Figure 2. From the solid-state NMR spectra, it can be seen that the solid NMR spectra of the raw materials MC and PET appear on the solid-state NMR spectra of the MC/ PET (1:1) composite film, and no other miscellaneous peaks appear. This shows that MC and PET are successfully compounded. There was no chemical reaction between MC and PET and solvent and between MC and PET during the dissolution and regeneration. The dissolution of both MC and PET in the solvent is a physical process.

3.3. XRD Analysis. The X-ray diffraction patterns can be observed in Figure 3 for MC, RPET, and MC/PET films. MC shows two broad bands and, also, good diffraction peaks at $2 \theta=8.9^{\circ}$ and $19.7^{\circ}[38,39]$, indicating the coexistence of amorphous and crystalline regions in the MC structure. The more broad peaks in the range of $2 \theta=12-34$ oare attributed to the amorphous PET $[3,40,41]$. In the XRD patterns of the $\mathrm{MC} / \mathrm{PET}$ composites, the diffraction signal for $\mathrm{MC}$ at $8.9^{\circ}$ is absent, and the intensity of the diffraction signal at $19.7^{\circ}$ is decreased. At the same time, the diffraction signal intensity for PET in the range of $2 \theta=12-34^{\circ}$ becomes weaker with an increase in the amount of $\mathrm{MC}$ in the MC/PET composites. The abovementioned results suggest that the crystallinity of $\mathrm{MC}$ and PET is reduced after the hybridization of MC with PET. Moreover, it is also found that compared with neat MC and PET, the $2 \theta$ values of MC and PET in the MC/PET films remain invariable, suggesting that $\mathrm{MC}$ hardly and/or weakly interacts with PET.

3.4. Thermogravimetric Analysis. Thermogravimetric analysis (TGA) is known to be an efficient method for estimating the thermal stability of various materials $[8,42]$. As such, the TGA curves of the MC/PET films along with RPET and original $\mathrm{MC}$ were determined in a nitrogen atmosphere and presented in Figure 4. MC begins to decompose at $343^{\circ} \mathrm{C}$ and 

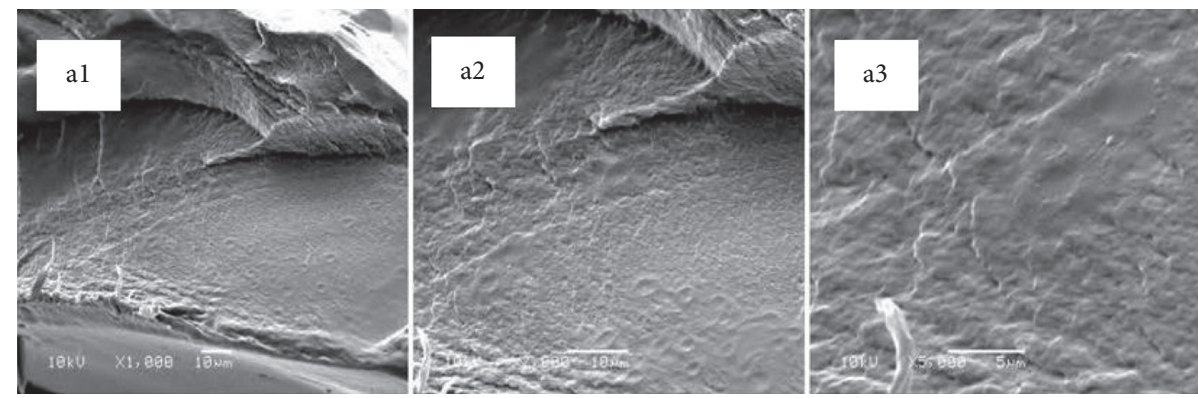

(a)
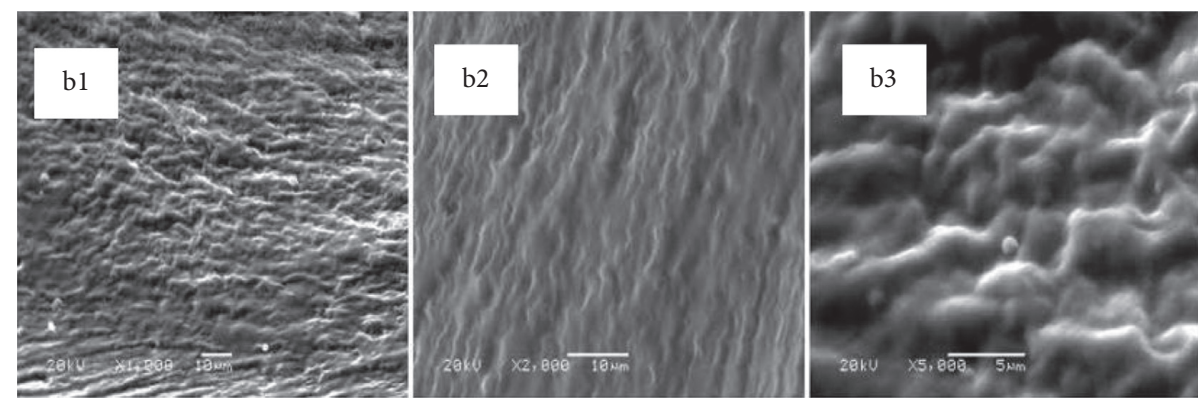

(b)
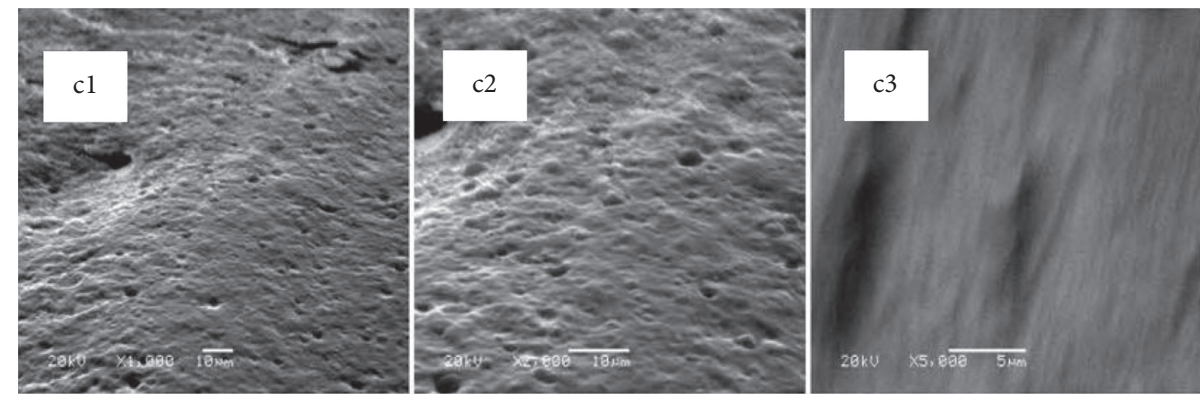

(c)
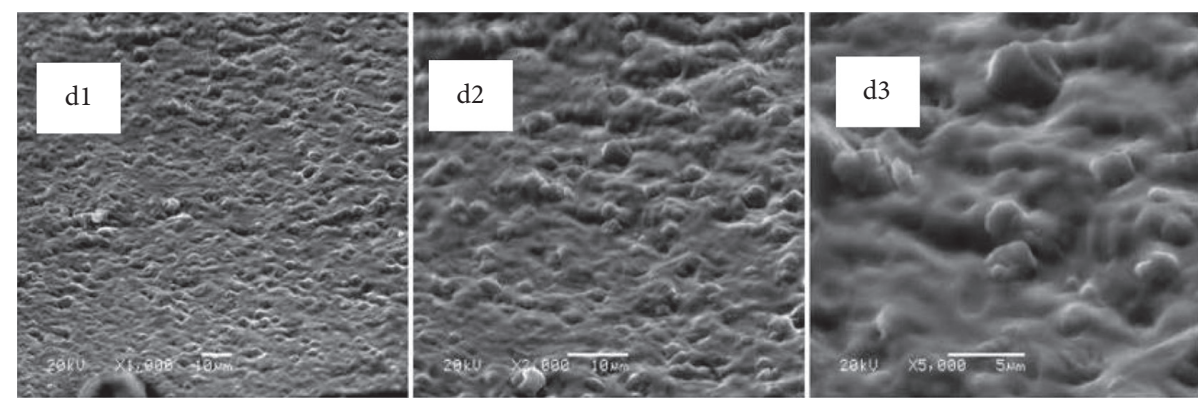

(d)
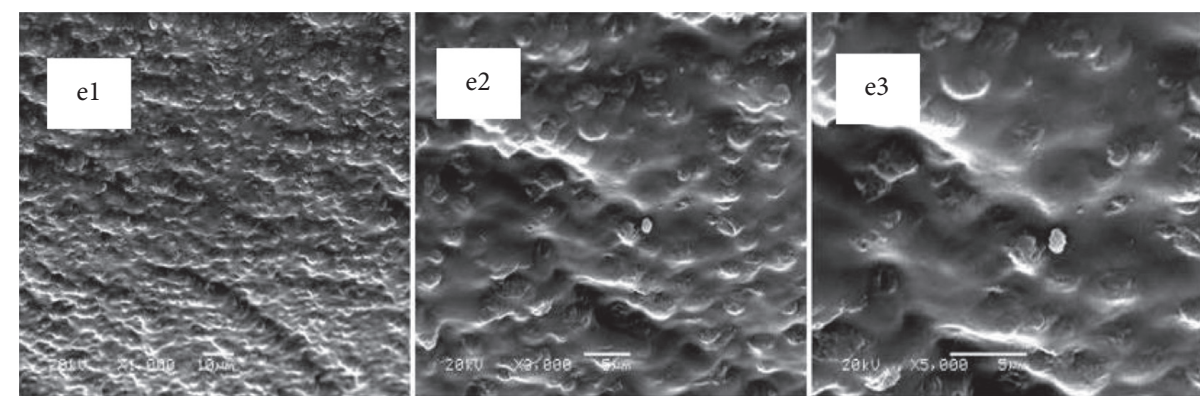

(e)

Figure 1: Continued. 

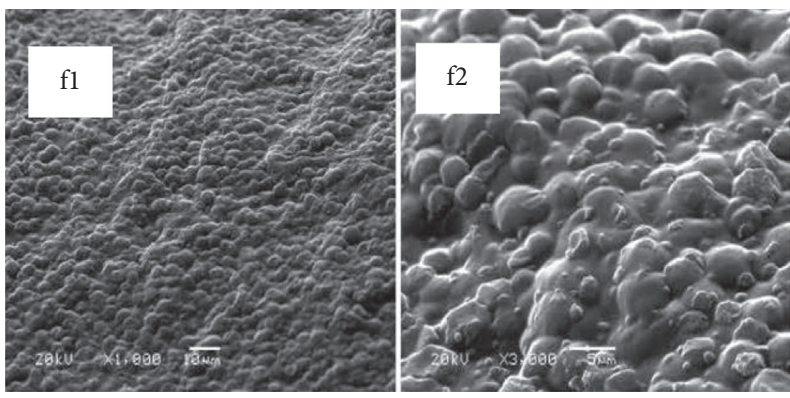

(f)
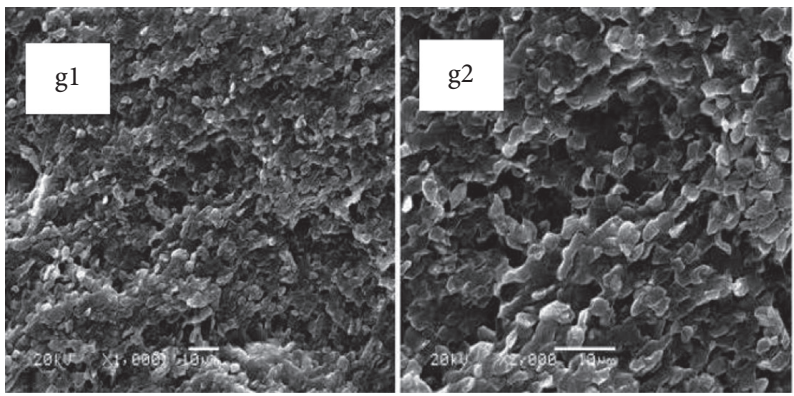

(g)
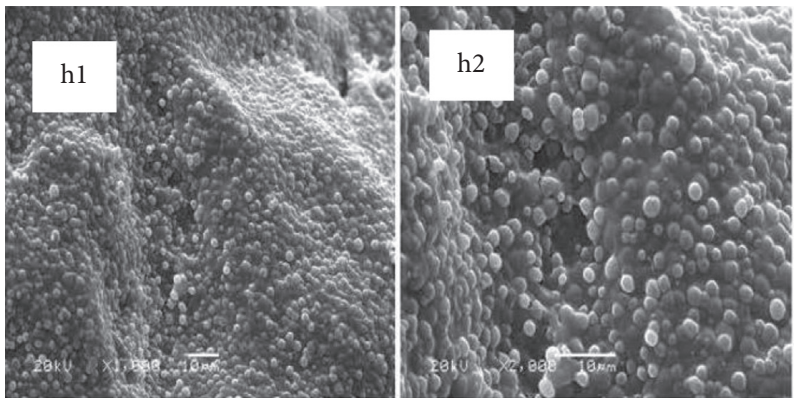

(h)
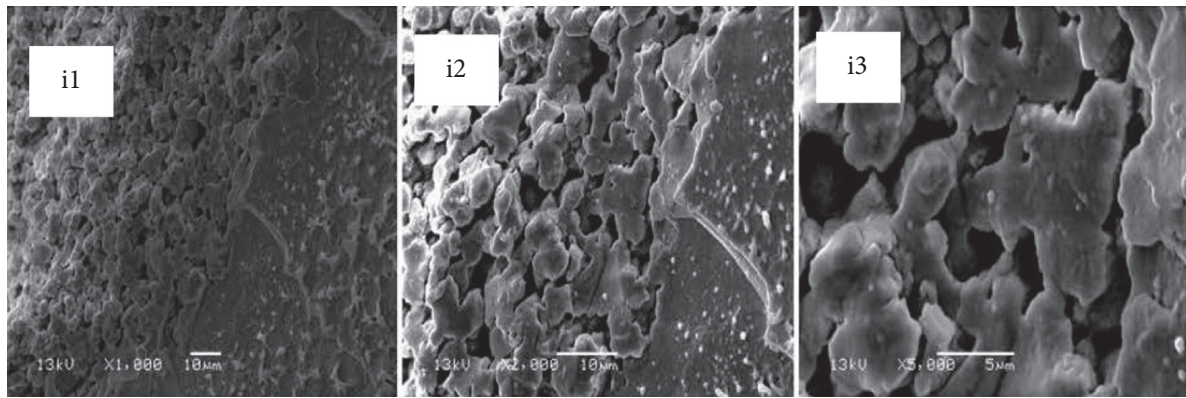

(i)

FIGURE 1: SEM images of fracture surfaces at various magnifications: (a) neat MC film; (b) MC/PET (99:1) film; (c) MC/PET (97:3) film; (d) MC/PET (95:5) film; (e) MC/PET (9:1) film. (f) MC/PET (7:3) film; (g) MC/PET (1:1) film; (h) MC/PET (3:7) film; and (i) MC/PET (1:9) film.

$424^{\circ} \mathrm{C}$ for RPET. Therefore, RPET shows higher thermal stability than MC. After MC was composited with PET, it was found that the thermal decomposition temperatures of the MC/PET films were higher those of $\mathrm{MC}\left(343^{\circ} \mathrm{C}\right)$ and lower than those of RPET $\left(424^{\circ} \mathrm{C}\right)$ and increased with an increase in the content of PET. The thermal decomposition temperatures were $347^{\circ} \mathrm{C}, 358^{\circ} \mathrm{C}, 359^{\circ} \mathrm{C}$, and $363^{\circ} \mathrm{C}$, corresponding to MC/PET (9:1), MC/PET (7:3), MC/PET $(1: 1)$, and MC/PET $(3: 7)$, respectively. At the same time, different from RPET and MC which showed one thermal decomposition stage, the MC/PET films displayed three stages of thermal decomposition behavior. The first weight loss within approximately $130^{\circ} \mathrm{C}$ was the evaluation of moisture. The second stage mainly corresponded to the 


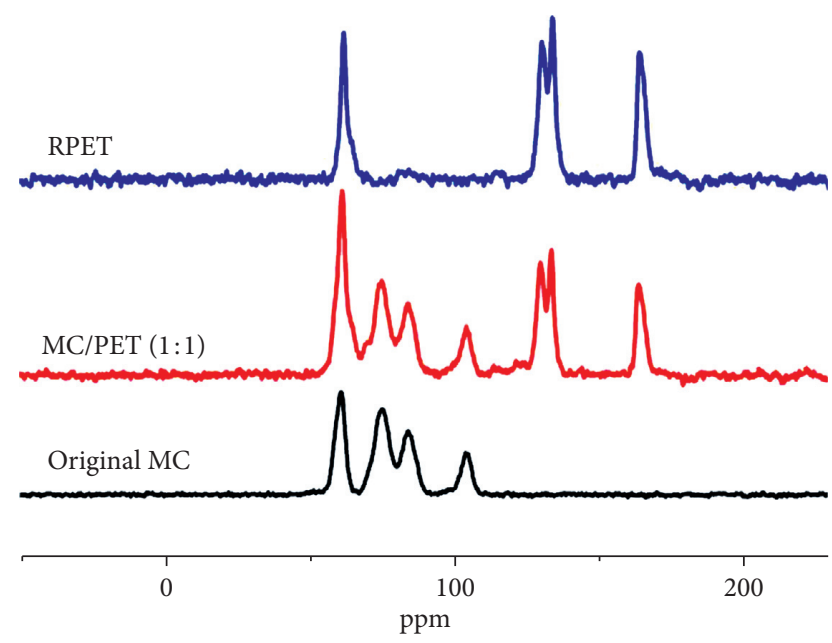

Figure 2: Solid-state ${ }^{13} \mathrm{C}$ NMR spectra of MC, MC/PET (1:1) film, and PET.

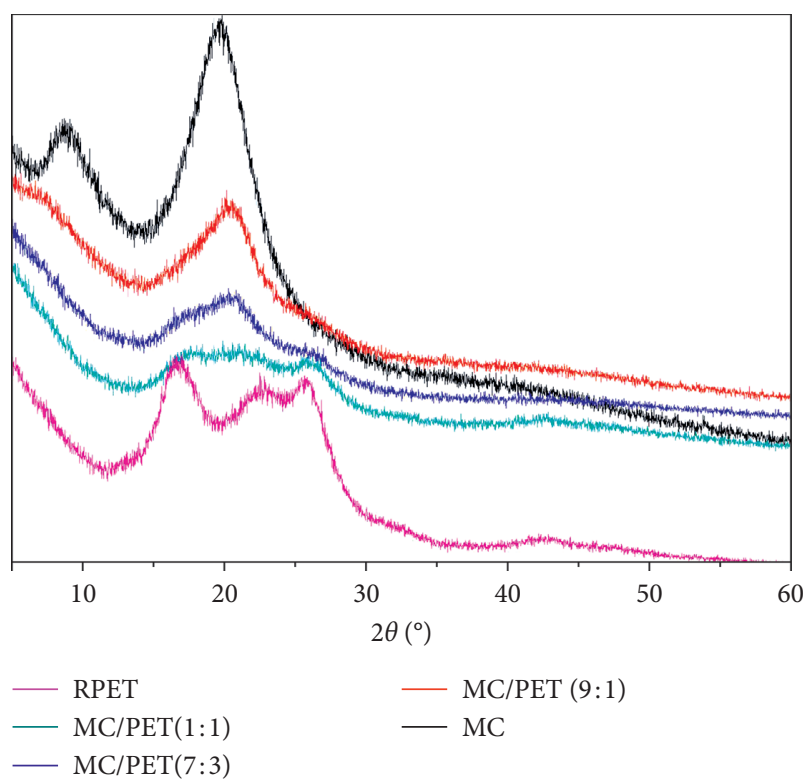

FIGURE 3: XRD patterns of original MC, RPET, and MC/PET films.

thermal decomposition of MC, and the third stage primarily for PET. Moreover, due to the higher thermostability of PET and the mutual effect, the thermal decomposition temperatures increased in the order MC/PET $(9: 1)<\mathrm{MC} / \mathrm{PET}(7: 3)$ $<\mathrm{MC} / \mathrm{PET}(1: 1)<\mathrm{MC} / \mathrm{PET}(3: 7)$.

3.5. MC/PET Mass Ratio Effect on Mechanical Properties. Mechanical properties such as tensile strength and elongation at break of the neat $\mathrm{MC}$ film and $\mathrm{MC} / \mathrm{PET}$ composite films with different MC/PET mass ratios have been determined, and presented in Figures 5 and 6, respectively. The fabricated MC/PET composites show apparently improved mechanical properties compared with neat $\mathrm{MC}$ at the mass ratio range from 99:1 to 9:1. Among them, the MC/PET (97:3) film shows maximum tensile strength value, and its tensile strength is higher than that of the neat MC film by

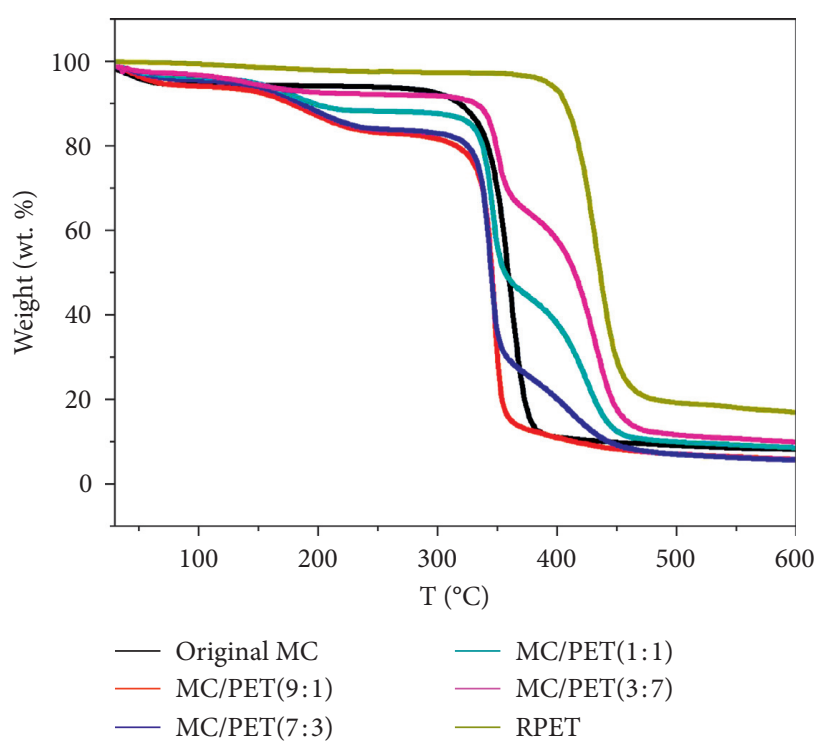

FIgUre 4: TGA curves of original MC, RPET, and MC/PET films.

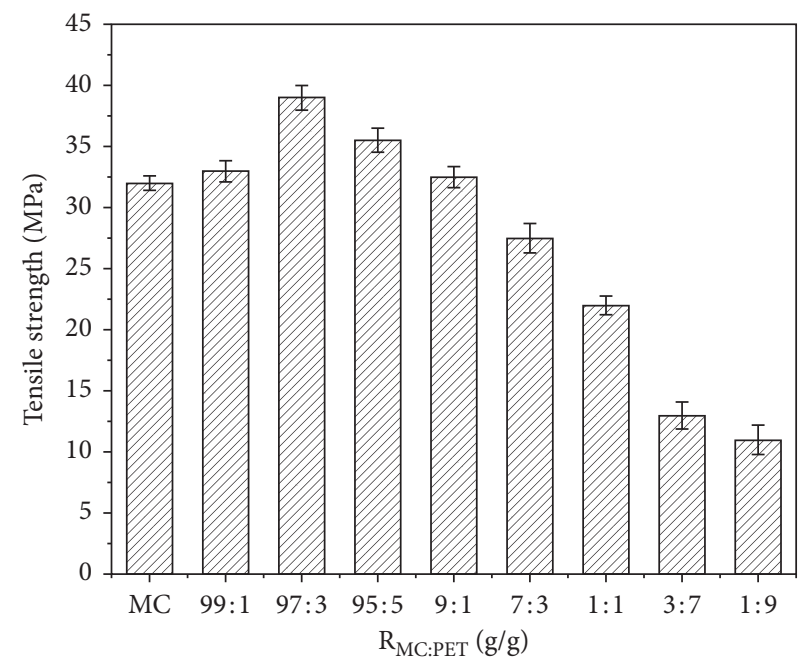

FIgUre 5: MC/PET mass ratio ( $\left.\mathrm{R}_{\mathrm{MC}: \mathrm{PET}}\right)$ dependent on tensile strength of the neat MC film and MC/PET films.

about $24 \%$. However, with further increase of the MC/PET mass ratio at the range from $9: 1$ to $1: 9$, the interspaces and stress concentrations increase, which act as crack initiation points during impact that decrease the impact strength after $97: 3 \mathrm{MC} / \mathrm{PET}$ mass ratio. In fact, this has been confirmed by the SEM observation by which when MC/PET mass ratio is equal to or greater than 95:5, apparent aggregation and phase separation are observed, producing interspaces and stress concentrations.

Meanwhile, with the increase in the content of PET in the $\mathrm{MC} / \mathrm{PET}$ composite, the elongation at break keeps increasing. The elongation at break of the MC/PET (1:9) composite reaches a maximum value of $79.6 \%$ and higher than that of the neat MC film by about $368 \%$. This suggests that PET can considerably improve the toughness of the MC/ PET composite. 


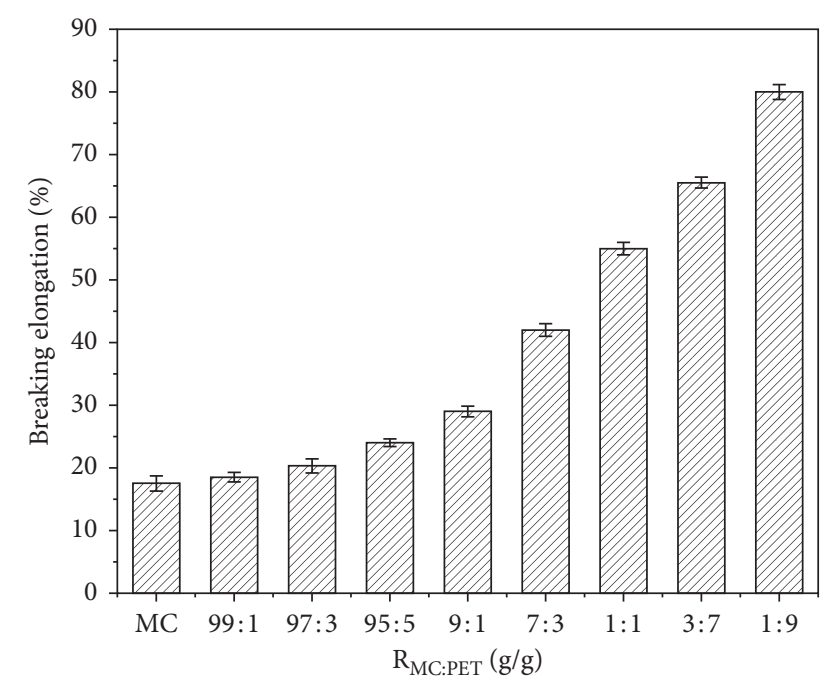

FIgURE 6: MC/PET mass ratio $\left(\mathrm{R}_{\mathrm{MC}: \mathrm{PET}}\right)$ dependent on breaking elongation of the neat MC film and MC/PET films.

\section{Conclusions}

This work presents a facile approach to fabricate an MC/PET composite using $\mathrm{MC}$ and waste plastic PET. The morphologies and properties are significantly affected by the $\mathrm{MC} / \mathrm{PET}$ mass ratio. 3\% of PET loading can considerably improve the tensile strength, and the elongation at break evidently increases with the MC/PET mass ratio. The crystallinities of MC and PET in the composites obviously decrease as compared with original MC and PET. The composite is thermally enough stable, and the thermal decomposition temperature ranges between $343^{\circ} \mathrm{C}$ and $424^{\circ} \mathrm{C}$. From ${ }^{13} \mathrm{C} \mathrm{NMR}$, it has been found that $\mathrm{MC}$ is physically blended with PET. The current findings open up new horizons for the application of waste plastics in fabricating ecofriendly sustainable green products.

\section{Data Availability}

The data used to support the findings of this study are included within the article.

\section{Conflicts of Interest}

The authors declare that there are no conflicts of interest regarding the publication of this paper.

\section{Acknowledgments}

The authors are grateful to the Changsha Science and Technology Plan (kq1902045) and SRTP Program, Henan University of Science and Technology (2019159).

\section{References}

[1] F. D. Alsewailem and J. K. Alrefaie, "Effect of contaminants and processing regime on the mechanical properties and moldability of postconsumer polyethylene terephthalate bottles," Waste Management, vol. 81, pp. 88-93, 2018.
[2] K. Chikaoui, M. Izerrouken, M. Djebara, and M. Abdesselam, "Polyethylene terephthalate degradation under reactor neutron irradiation," Radiation Physics and Chemistry, vol. 130, pp. 431-435, 2017.

[3] G. Galo Silva, M. L. d. C. Valente, L. Bachmann, and A. C. dos Reis, "Use of polyethylene terephthalate as a prosthetic component in the prosthesis on an overdenture implant," Materials Science and Engineering: C, vol. 99, pp. 1341-1349, 2019.

[4] X. Zhou, J. Deng, R. Yang et al., "Facile preparation and characterization of fibrous carbon nanomaterial from waste polyethylene terephthalate," Waste Management, vol. 107, pp. 172-181, 2020.

[5] N. K. Bui, T. Satomi, and H. Takahashi, "Recycling woven plastic sack waste and PET bottle waste as fiber in recycled aggregate concrete: an experimental study," Waste Management, vol. 78, pp. 79-93, 2018.

[6] M. P. Gashti, S. Moradian, A. Rashidi, and M.-E. Yazdanshenas, "Dispersibility of hydrophilic and hydrophobic nano-silica particles in polyethylene terephthalate films: evaluation of morphology and thermal properties," Polymers and Polymer Composites, vol. 23, no. 5, pp. 285-296, 2015.

[7] M. Parvinzadeh Gashti, D. Hegemann, M. Stir, and J. Hulliger, "Thin film plasma functionalization of polyethylene terephthalate to induce bone-like hydroxyapatite nanocrystals," Plasma Processes and Polymers, vol. 11, no. 1, pp. 37-43, 2014.

[8] D. Wang, B. Yang, Q.-T. Chen et al., "A facile evaluation on melt crystallization kinetics and thermal properties of lowdensity polyethylene (LDPE)/recycled polyethylene terephthalate (RPET) blends," Advanced Industrial and Engineering Polymer Research, vol. 2, no. 3, pp. 126-135, 2019.

[9] S. Aoyama, I. Ismail, Y. T. Park, Y. Yoshida, C. W. Macosko, and T. Ougizawa, "Polyethylene terephthalate/trimellitic anhydride modified graphene nanocomposites," ACS Applied Nano Materials, vol. 1, no. 11, pp. 6301-6311, 2018.

[10] S. Aoyama, Y. T. Park, T. Ougizawa, and C. W. Macosko, "Melt crystallization of poly(ethylene terephthalate): comparing addition of graphene vs. carbon nanotubes," Polymer, vol. 55, no. 8, pp. 2077-2085, 2014.

[11] S. Bandla and J. C. Hanan, "Microstructure and elastic tensile behavior of polyethylene terephthalate-exfoliated graphene nanocomposites," Journal of Materials Science, vol. 47, no. 2, pp. 876-882, 2012.

[12] R. Feng, G. Guan, W. Zhou, C. Li, D. Zhang, and Y. Xiao, "In situ synthesis of poly(ethylene terephthalate)/graphene composites using a catalyst supported on graphite oxide," Journal of Materials Chemistry, vol. 21, no. 11, pp. 3931-3939, 2011.

[13] M. Li and Y. G. Jeong, "Poly(ethylene terephthalate)/exfoliated graphite nanocomposites with improved thermal stability, mechanical and electrical properties," Composites Part A: Applied Science and Manufacturing, vol. 42, no. 5, pp. 560-566, 2011.

[14] H.-B. Zhang, W.-G. Zheng, Q. Yan et al., "Electrically conductive polyethylene terephthalate/graphene nanocomposites prepared by melt compounding," Polymer, vol. 51, no. 5, pp. 1191-1196, 2010.

[15] N. S. Allen, M. Edge, M. Mohammadian, and K. Jones, "Physicochemical aspects of the environmental degradation of poly(ethylene terephthalate)," Polymer Degradation and Stability, vol. 43, no. 2, pp. 229-237, 1994.

[16] R. Sharma and P. P. Bansal, "Use of different forms of waste plastic in concrete-a review," Journal of Cleaner Production, vol. 112, pp. 473-482, 2016. 
[17] M. M. Lubna, K. S. Salem, M. Sarker, and M. A. Khan, "Modification of thermo-mechanical properties of recycled PET by vinyl acetate (VAc) monomer grafting using gamma irradiation," Journal of Polymers and the Environment, vol. 26, no. 1, pp. 83-90, 2018.

[18] R. C. Nonato and B. C. Bonse, "A study of PP/PET composites: factorial design, mechanical and thermal properties," Polymer Testing, vol. 56, pp. 167-173, 2016.

[19] R. S. Chen, S. Ahmad, and S. Gan, "Characterization of recycled thermoplastics-based nanocomposites: polymer-clay compatibility, blending procedure, processing condition, and clay content effects," Composites Part B: Engineering, vol. 131, pp. 91-99, 2017.

[20] M. N. Salleh, R. S. Chen, M. H. Ab Ghani, F. H. Kasim, and A. Sahrim, "Preparation and characterization of high-density polyethylene blends and recycled poly (ethylene terephthalate)," Applied Mechanics and Materials, vol. 695, pp. 131-134, 2014.

[21] R. S. Chen, S. Ahmad, and S. Gan, "Rice husk bio-filler reinforced polymer blends of recycled HDPE/PET: threedimensional stability under water immersion and mechanical performance," Polymer Composites, vol. 39, no. 8, pp. 2695$2704,2016$.

[22] N. R. Nik Hassan, N. M. Ismail, S. Ghazali, and D. M. Nuruzzaman, "Thermal properties of polyethylene reinforced with recycled-poly (ethylene terephthalate) flakes," IOP Conference Series: Materials Science and Engineering, vol. 342, Article ID 12094, 2018.

[23] R. Shamsi, G. Mir Mohamad Sadeghi, H. Vahabi et al., "Hopes beyond PET recycling: environmentally clean and engineeringly applicable," Journal of Polymers and the Environment, vol. 27, no. 11, pp. 2490-2508, 2019.

[24] P.-J. He, H.-X. Pu, L.-M. Shao, and H. Zhang, "Impact of colandfill proportion of bottom ash and municipal solid waste composition on the leachate characteristics during the acidogenesis phase," Waste Management, vol. 69, pp. 232241, 2017.

[25] P.-J. He, "Municipal solid waste in rural areas of developing country: do we need special treatment mode?" Waste Management, vol. 32, no. 7, pp. 1289-1290, 2012

[26] N. A. Al-Tayyar, A. M. Youssef, and R. Al-hindi, "Antimicrobial food packaging based on sustainable Bio-based materials for reducing foodborne Pathogens: a review," Food Chemistry, vol. 310, Article ID 125915, 2019.

[27] H. Moustafa, A. M. Youssef, N. A. Darwish, and A. I. AbouKandil, "Eco-friendly polymer composites for green packaging: future vision and challenges," Composites Part B: Engineering, vol. 172, pp. 16-25, 2019.

[28] A. M. Youssef and S. M. El-Sayed, "Bionanocomposites materials for food packaging applications: concepts and future outlook," Carbohydrate Polymers, vol. 193, pp. 19-27, 2018.

[29] A. Boumail, S. Salmieri, E. Klimas, P. O. Tawema, J. Bouchard, and M. Lacroix, "Characterization of trilayer antimicrobial diffusion films (ADFs) based on methylcellulose-polycaprolactone composites," Journal of Agricultural and Food Chemistry, vol. 61, no. 4, pp. 811-821, 2013.

[30] R. A. Khan, S. Salmieri, D. Dussault et al., "Production and properties of nanocellulose-reinforced methylcellulose-based biodegradable films," Journal of Agricultural and Food Chemistry, vol. 58, no. 13, pp. 7878-7885, 2010.

[31] E. Matta, M. J. Tavera-Quiroz, and N. Bertola, "Active edible films of methylcellulose with extracts of green apple (Granny Smith) skin," International Journal of Biological Macromolecules, vol. 124, pp. 1292-1298, 2019.
[32] B. Das, A. Basu, S. Maji et al., "Nanotailored hyaluronic acid modified methylcellulose as an injectable scaffold with enhanced physico-rheological and biological aspects," Carbohydrate Polymers, vol. 237, p. 116146, 2020.

[33] W. Tan, J. Zhang, X. Zhao, Q. Li, F. Dong, and Z. Guo, "Preparation and physicochemical properties of antioxidant chitosan ascorbate/methylcellulose composite films," International Journal of Biological Macromolecules, vol. 146, pp. 53-61, 2020.

[34] M. Jouyandeh, F. Tikhani, N. Hampp et al., "Highly curable self-healing vitrimer-like cellulose-modified halloysite nanotube/epoxy nanocomposite coatings," Chemical Engineering Journal, vol. 396, p. 125196, 2020.

[35] H. Spieser, A. Denneulin, D. Deganello, D. Gethin, R. Koppolu, and J. Bras, "Cellulose nanofibrils and silver nanowires active coatings for the development of antibacterial packaging surfaces," Carbohydrate Polymers, vol. 240, p. 116305, 2020.

[36] A. Khosravi, A. Fereidoon, M. M. Khorasani et al., "Soft and hard sections from cellulose-reinforced poly (lactic acid)based food packaging films: a critical review," Food Packaging and Shelf Life, vol. 23, p. 100429, 2020.

[37] A. Hejna, M. Sulyman, M. Przybysz, M. R. Saeb, M. Klein, and K. Formela, "On the correlation of lignocellulosic filler composition with the performance properties of poly ( $\varepsilon$-caprolactone) based biocomposites," Waste and Biomass Valorization, vol. 11, no. 4, pp. 1467-1479, 2020.

[38] H. Liu, C. Liu, S. Peng, B. Pan, and C. Lu, "Effect of polyethyleneimine modified graphene on the mechanical and water vapor barrier properties of methyl cellulose composite films," Carbohydrate Polymers, vol. 182, pp. 52-60, 2018.

[39] A. Pinotti, M. A. García, M. N. Martino, and N. E. Zaritzky, "Study on microstructure and physical properties of composite films based on chitosan and methylcellulose," Food Hydrocolloids, vol. 21, no. 1, pp. 66-72, 2007.

[40] Z. Zhang, Z. Zhao, Z. Zheng et al., "Functionalization of polyethylene terephthalate fabrics using nitrogen plasma and silk fibroin/chitosan microspheres," Applied Surface Science, vol. 495, p. 143481, 2019.

[41] Y. Zhang, H. Jiang, K. Wang, H. Wang, and C. Wang, "Green flotation of polyethylene terephthalate and polyvinyl chloride assisted by surface modification of selective $\mathrm{CaCO}_{3}$ coating," Journal of Cleaner Production, vol. 242, p. 118441, 2020.

[42] K. Gaska, X. Xu, S. Gubanski, and R. Kádár, "Electrical, mechanical, and thermal properties of ldpe graphene nanoplatelets composites produced by means of melt extrusion process," Polymers, vol. 9, no. 12, p. 11, 2017. 